\title{
Excessive Sodium Bicarbonate Infusion May Result in Osmotic Demyelination Syndrome During Treatment of Diabetic Ketoacidosis: A Case Report
}

\author{
Hui-Chi Hsieh · Shin-Hwar Wu • Chun-Ching Chiu • Keng-Chu Ko
}

Received: January 28, 2019 / Published online: March 6, 2019

(C) The Author(s) 2019

\begin{abstract}
Introduction: We present a case wherein diabetic ketoacidosis (DKA) was treated with a large amount of sodium bicarbonate and potassium chloride, resulting in the development of osmotic demyelination syndrome (ODS).

Case presentation: Our patient was a 29 -yearold male with a history of post-surgical repair for ventricular septal defect. Upon arrival, the patient's Glasgow Coma Scale (GCS) score was E2M4V3. Laboratory examinations revealed leukocytosis, severe metabolic acidosis, hypokalemia, and hyperglycemia. His consciousness status and hemodynamics improved after resuscitation (GCS: E3M6Ve). However, they declined at the 40th hour of admission and
\end{abstract}

Enhanced Digital Features To view enhanced digital features for this article go to https://doi.org/10.6084/ m9.figshare.7770347.

H.-C. Hsieh · S.-H. Wu · C.-C. Chiu · K.-C. Ko (ه) Division of Critical Care, Department of Internal Medicine, Changhua Christian Hospital, Changhua, Taiwan

e-mail: garykou@gmail.com

C.-C. Chiu

Department of Neurology, Changhua Christian Hospital, Changhua, Taiwan

K.-C. Ko

Division of Nephrology, Department of Internal Medicine, Changhua Christian Hospital, Changhua, Taiwan dropped to GCS E2M2Ve. Magnetic resonance imaging revealed multifocal abnormal signal intensity changes in the whole brain stem. The diagnosis of type 1 diabetes mellitus was made during the hospitalization period. The patient exhibited improved consciousness status after 17-day medical care at the ICU.

Conclusions: We recommend that in the case of DKA, the correction of hypokalemia should be prioritized during treatment. Sodium bicarbonate infusion should be reserved for $\mathrm{pH}$ $<6.9$. In addition, close monitoring of the serum sodium level and prompt actions to lower it if it exceeds the threshold may be necessary.

Keywords: Case report; Diabetic ketoacidosis; Hypernatremia; Osmotic demyelination syndrome; Sodium bicarbonate

\section{INTRODUCTION}

Central pontine myelinolysis (CPM) was first described in 1959 by Adams et al. [1]. It is also known as osmotic demyelination syndrome (ODS), which includes CPM and extrapontine myelinolysis (EPM) [2]. The clinical presentation of ODS includes various neurologic symptoms including consciousness disturbance, flaccid quadriplegia, dysarthria, and dysphagia [2]. This neurologic disorder has often been associated with overly corrected hyponatremia 
[3]; however, other factors such as alcoholism [4], malnutrition [5], and electrolyte disturbance $[4,6]$ have also been described.

The pathogenesis of ODS is poorly understood [2]. However, a possible hypothesis is that the glial cells are swollen during chronic hyponatremia, and treatment with hypertonic saline creates a hypertonic state and causes shrinkage of cells. Simultaneously, substances such as cytokines and immunoglobins were released, triggering oligodendrocyte degeneration and ultimately myelin destruction [2].

Diabetic ketoacidosis (DKA) and hyperglycemic hyperosmolar state (HHS) are diabetic emergencies that often cause electrolyte and osmolality changes, which are theoretically compatible with the etiologies of ODS. Previously, ODS was documented as the initial presentation of DKA [7]. However, osmotic fluids, such as sodium bicarbonate and potassium chloride, used in the treatment of DKA may also provide similar effects to hypertonic saline. Herein, we present a case wherein DKA was treated with a large amount of sodium bicarbonate and potassium chloride, which resulted in the development of ODS.

\section{CASE PRESENTATION}

A 29-year-old male with a history of post-surgical repair for ventricular septal defect (VSD) contacted the emergency department of a branch hospital of Changhua Christian Hospital because of dyspnea and altered consciousness for 3 days. Symptoms of poor response to stimulations and lethargy occurred gradually. No medications or street drugs were administered. Upon arrival, the patient's Glasgow Coma Scale (GCS) score was reported as E2M4V3; furthermore, hypotension $(80 / 39 \mathrm{mmHg})$ and hypothermia $\left(34.5^{\circ} \mathrm{C}\right)$ were noted. Laboratory examinations revealed leukocytosis $(15,000 / \mu \mathrm{l})$, severe metabolic acidosis $\left(\mathrm{pH}:\right.$ 7.04, $\mathrm{PCO}_{2}$ : $\left.11.2 \mathrm{mmHg}, \mathrm{HCO}_{3}{ }^{-}: 3.1 \mathrm{mmol} / \mathrm{l}\right)$, hypokalemia $(2.0 \mathrm{mmol} / \mathrm{l})$, and hyperglycemia $(646 \mathrm{mg} / \mathrm{dl})$. Serum sodium level was $138 \mathrm{mmol} / \mathrm{l}$ unadjusted and $148 \mathrm{mmol} / \mathrm{l}$ after adjustment according to the formula of an increase of $1.6 \mathrm{mmol} / \mathrm{l}$ per $100 \mathrm{mg} / \mathrm{dl}$ of serum glucose.
Initially, four ampules of sodium bicarbonate $(7 \%, 20 \mathrm{ml}$ each ampule) and one ampule of potassium chloride (20 meq) were administered. The patient was admitted to the ICU because of unstable hemodynamics. Insulin was continuously infused, and intubation was performed because of persistent hypotension and altered consciousness. Large amounts of isotonic and hypertonic intravenous fluids were administered for resuscitation $(2500 \mathrm{ml} \quad 0.9 \%$ normal saline, $2000 \mathrm{ml}$ 6\% hydroxyethyl starch fluid, and $4000 \mathrm{ml}$ Ringer's solution for 24-h duration). In addition, norepinephrine and epinephrine were continuously infused. Severe hypokalemia was reported, and multiple ventricular premature complexes (VPCs) were witnessed. In total, 440 meq of potassium chloride was administered. Notably, his consciousness status (GCS: E3M6Ve) and hemodynamics improved following the resuscitation. Sequential blood sampling results are presented in Fig. 1.

However, the patient's consciousness status declined at the 40th hour of admission (GCS: E2M2Ve). Accordingly, emergent brain computed tomography was performed, and he was transferred to the medical center for magnetic resonance imaging (MRI) evaluation.

MRI results revealed multifocal abnormal signal intensity changes in the whole brain stem; these lesions involved the lower midbrain, whole pons, and upper medulla oblongata. The lesions presented as faint signal on the apparent diffusion coefficient (ADC) map and brightened up on diffusion-weighted images(DWI), fluid-attenuated inversion recovery(FLAIR), and T2WI MRI images. Based on these findings, ODS was established (Fig. 2). Later, type 1 diabetes mellitus was diagnosed during the hospitalization period.

The patient exhibited improved consciousness status following 17-day medical care at the ICU; nonetheless, he was ventilator dependent and subsequently was placed in a respiratory care unit for another 25 days. Although the ventilator was gradually weaned, the patient still needed assistance and rehabilitation at the time of discharge from the hospital. The case report was approved by the institutional review board committee of Changhua Christian 


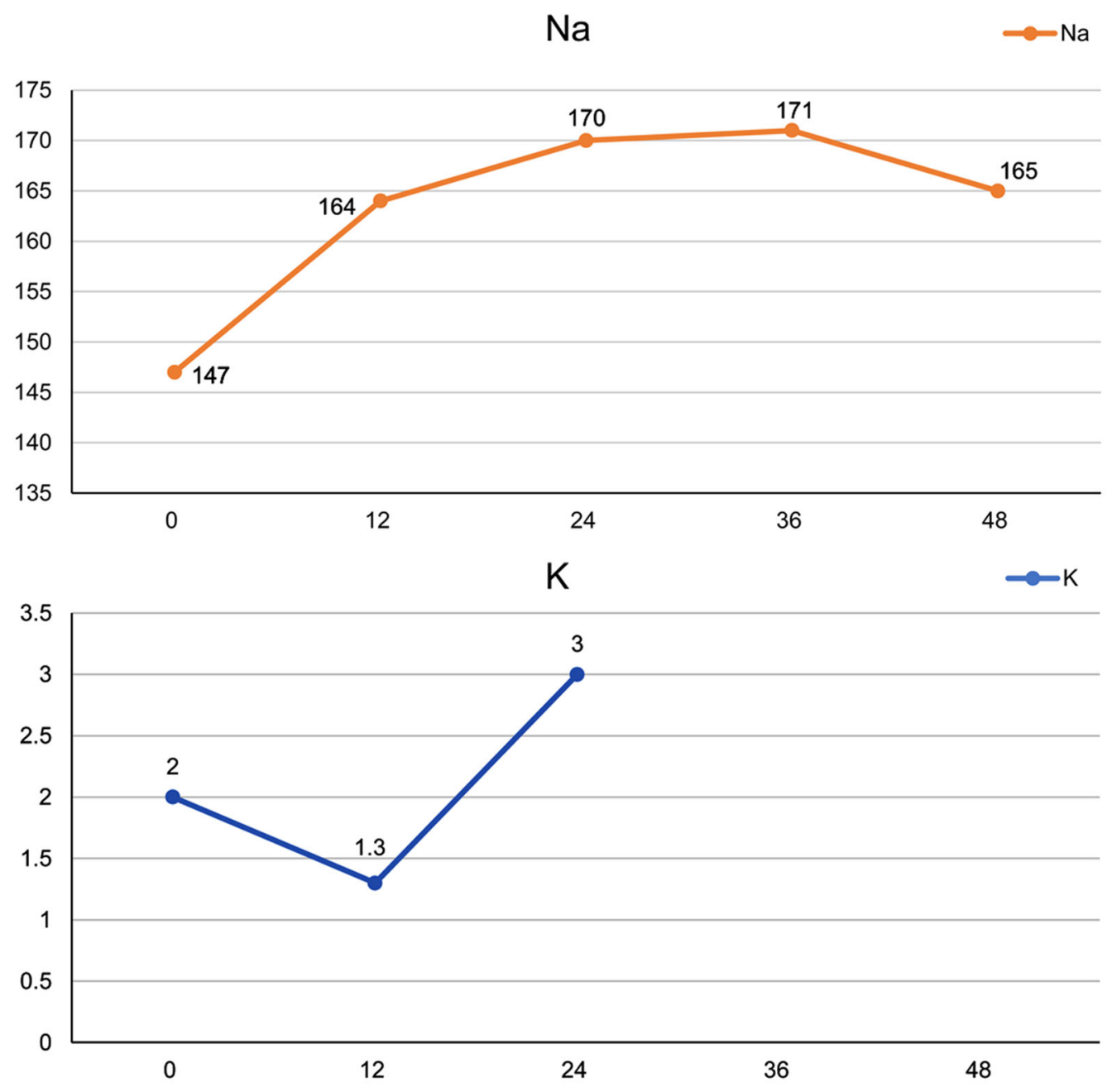

Fig. 1 Sequential blood sampling of the patient. a Serum sodium $(\mathrm{Na})$ level. b Serum potassium $(\mathrm{K})$ level. The horizontal axis represents hours after the emergency room

Hospital (reference no. 181114). Informed consent was obtained from the individual participant for being included in the study. Written informed consent was obtained from the patient for the publication of this case report and any accompanying images.

\section{DISCUSSION AND CONCLUSION}

Several case reports have described the relationship between hyperglycemia and ODS $[3,8,9]$. In one such case report [8], a type 2 diabetic and cirrhotic patient presented with visit. The units of $\mathrm{Na}$ and $\mathrm{K}$ are $\mathrm{mmol} / \mathrm{l}$. The $\mathrm{Na}$ results were corrected by the formula of an increase of $1.6 \mathrm{mmol} / \mathrm{l}$ per $100 \mathrm{mg} / \mathrm{dl}$ of serum glucose

several neurologic symptoms following ingestion of large amounts of sugar-containing foods and was diagnosed with ODS [8]. During admission, the patient had serum sodium levels in the range of $133-144 \mathrm{mmol} / \mathrm{l}$. The authors concluded that ODS resulted from sudden hyperglycemia. In another instance [3], a patient presented with a serum glucose level of $106 \mathrm{mmol} / \mathrm{l}(1908 \mathrm{mg} / \mathrm{dl})$ that declined to $60 \mathrm{mmol} / \mathrm{l}(1080 \mathrm{mg} / \mathrm{dl})$ in $6 \mathrm{~h}$. The serum sodium level simultaneously elevated from 135 to $159 \mathrm{mmol} / \mathrm{l}$. Both cases did not report hyponatremia but displayed abrupt serum osmolality changes. 
A

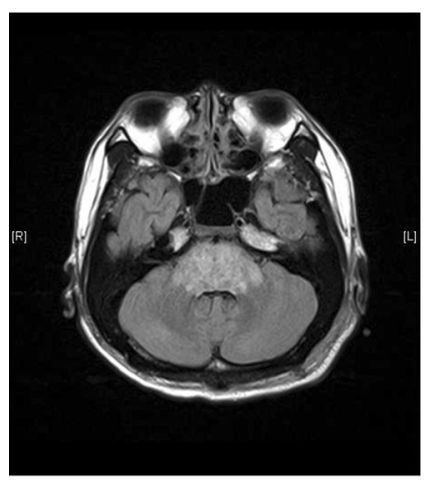

D

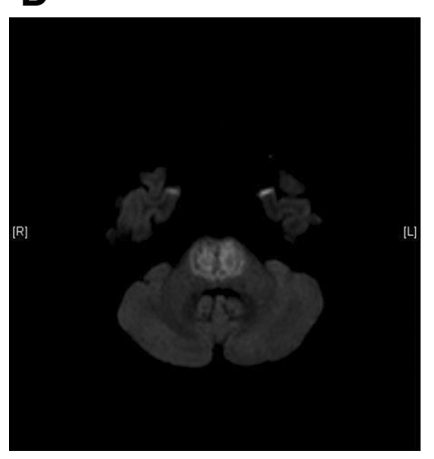

B

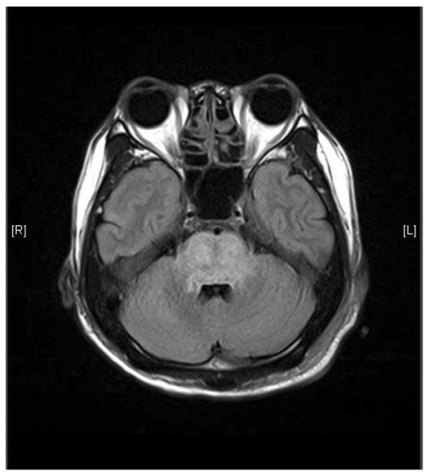

E

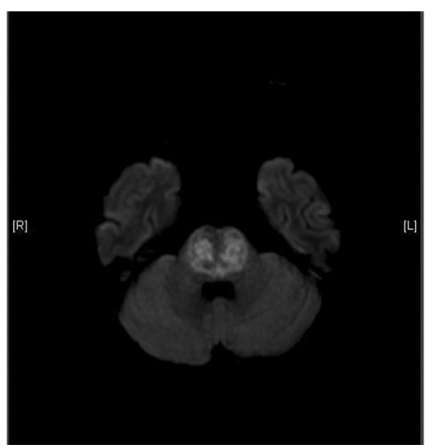

C

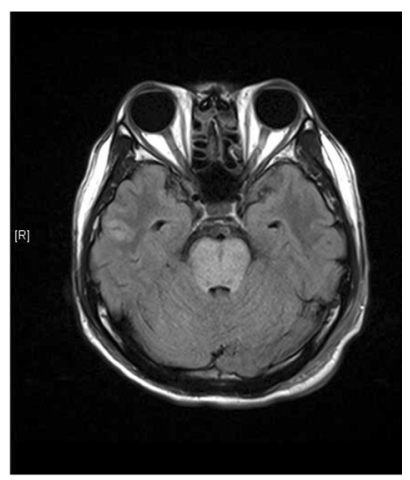

$\mathbf{F}$

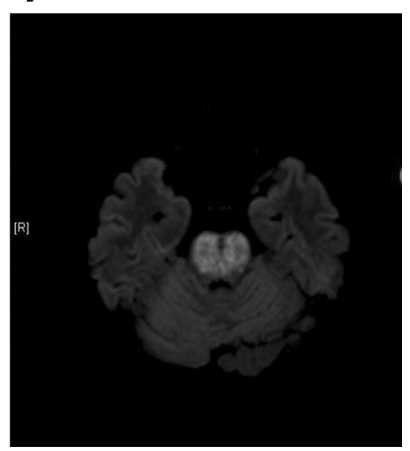

Fig. 2 a-c T2-weighted fluid-attenuated inversion recovery magnetic resonance imaging (MRI) images. $\mathbf{d}-\mathbf{f}$ Diffusionweighted magnetic resonance imaging shows multifocal

Treatment of DKA involves the administration of intravenous fluids, potassium supplements, and insulin [10]. A systematic review concluded that bicarbonate therapy provided no clinical advantages in the management of DKA [11]. A report suggested that bicarbonate infusion can be administered if the serum $\mathrm{pH}$ is $<6.9$ [10 12] to justify the deleterious effect of acidemia. However, another review conducted in 2011 stated the absence of sufficient evidence to support the therapy [11]. In addition, once administered, sodium bicarbonate infusion was initially recommended at the dose of $100 \mathrm{mmol}$ and later at a dose of $20 \mathrm{mmol}$ for every $2 \mathrm{~h}$ until the serum $\mathrm{pH}$ was $>7.0$ [12]. Furthermore, some side effects of bicarbonate therapy have been reported, including cerebral edema [13], hypokalemia, and paradoxical central nervous system acidosis [12].

A case report on the association between rapid sodium bicarbonate supplement and ODS abnormal signal intensity change in the whole brain stem; these lesions involve the parts from the lower midbrain and whole pons to the upper medulla oblonganta

has been published [14], but not on the DKA status. The case patient, who was later diagnosed with renal tubular acidosis, was intravenously administered $480 \mathrm{meq}$ sodium bicarbonate; consequently, the patient's serum sodium increased from 142.8 to $172.8 \mathrm{mmol} / \mathrm{l}$. The symptoms of ODS developed 6 days following the treatment.

Hypokalemia has been reported in association with ODS at various serum sodium levels $[15,16,17]$. Lohr et al. reported a series of cases and suggested hypokalemia to be associated with the development of ODS and correction of hypokalemia prior to the rectification of hyponatremia [15]. Koul et al. reported a case of severe hyponatremia and hypokalemia, but the correction speed of the serum sodium level did not exceed the recommendations $(<8 \mathrm{mmol} / \mathrm{l}$ in $24 \mathrm{~h}$ ) [16]. In 2003, Sugimoto et al. reported a case of anorexia nervosa with a normal serum sodium level $(140 \mathrm{mmol} / \mathrm{l})$ and hypokalemia 
(2.8 mmol/l) [17]. Fluctuation of the serum potassium level was documented.

The underlying mechanism through which serum hypokalemia influences the development of ODS is still unclear. Lohr et al. proposed a theory suggesting that a decreased NaK-ATPase level during hypokalemia predisposes the cell to osmotic stress injury [15].

In our case, there were several possible insults related to ODS: (1) development of DKA and dehydration; (2) a large quantity of sodium supplement (including sodium bicarbonate), which exceeded the suggested doses and enormous amounts of hypertonic fluid resuscitation; (3) serum hypokalemia, followed by a large volume of potassium chloride infusion. Whether the DKA status or sodium supplement was the main cause of ODS remains unclear. The DKA status may have caused cell shrinkage, as mentioned above. However, although the patient had altered consciousness at the time of presentation, his consciousness status improved subsequently. The initial resuscitation may have helped in enhancing tissue perfusion and subsequently the consciousness level. Hence, it is more likely that ODS developed during the following hospital courses. A large amount of osmotic electrolyte supplementation may have played a causative role.

We often encounter severe metabolic acidosis status in the emergency room setting or ICU, and sodium bicarbonate infusion is considered an important initial treatment to correct the acid-base status. In our case, a total of 30 ampules of sodium bicarbonate was administered over a $16-\mathrm{h}$ period. The sodium content of these fluids was 510 meq, which was equal to that of 11 of $3 \%$ sodium chloride. Frequent VPCs and hypotension also interfered with the clinician's decision. First-line clinicians may attribute this status to severe hypokalemia and acidosis and liberally prescribe sodium bicarbonate and potassium supplements, with the expectation of correcting the electrolyte disturbance as early as possible. However, osmotic changes caused by sodium bicarbonate and potassium chloride remain unaddressed.

It is widely known that ODS is often linked to the rapid correction of hyponatremia, and intensive monitoring of the serum sodium level has been suggested for ODS $[18,19]$. Nevertheless, in the clinical setting of DKA, only potassium monitoring has been highlighted [12]. Our case implies that not only potassium but also sodium levels must be monitored carefully in the first few hours of resuscitation and that clinicians should be aware of the possibility of a rapid increase in the serum sodium level. In lifethreatening conditions, potassium supplements should primarily be administered as indicated by a previous report [12]. The use of sodium bicarbonate should be refrained until the serum $\mathrm{pH}$ decreases to $<6.9$.

DKA with concurrent hypokalemia, arrhythmia, and unstable hemodynamics could be quite challenging for clinicians. The correction of hypokalemia should receive priority during treatments. Sodium bicarbonate infusion should be reserved for $\mathrm{pH}<6.9$. Close monitoring of the serum sodium level and prompt actions to lower it if it exceeds the threshold may be necessary.

\section{ACKNOWLEDGEMENTS}

We thank the participants of the study.

Funding. No funding or sponsorship was received for this study or publication of this article. The article processing charges were funded by the authors.

Authors. All named authors meet the International Committee of Medical Journal Editors (ICMJE) criteria for authorship for this article, take responsibility for the integrity of the work as a whole, and have given their approval for this version to be published.

Authors' contributions. $\mathrm{HCH}$ was involved in patient care, writing, imaging, and laboratory data gathering. KCK was involved in writing and giving academic suggestions regarding nephrology, including hyponatremia and its management. SHW was involved in patient care and data gathering and suggestions of clinical problems encountered. CCC was involved in suggestions for the discussion, neurologic consultation, and image interpretation. 
Disclosures. Hui-Chi Hsieh, Shin-Hwar Wu, Chun-Ching Chiu, and Keng-Chu Ko have nothing to disclose.

Compliance with Ethics Guidelines. The case report was approved by the institutional review board committee of Changhua Christian Hospital. The reference no. is 181114. Informed consent was obtained from the individual participant for being included in the study. Written informed consent was obtained from the patient for the publication of this case report and any accompanying images.

Data Availability. The data that support the findings of this case were kept confidential for patient privacy.

Open Access. This article is distributed under the terms of the Creative Commons Attribution-NonCommercial 4.0 International License (http://creativecommons.org/licenses/ by-nc/4.0/), which permits any noncommercial use, distribution, and reproduction in any medium, provided you give appropriate credit to the original author(s) and the source, provide a link to the Creative Commons license, and indicate if changes were made.

\section{REFERENCES}

1. Adams RD, Victor M, Mancall EL. Central pontine myelinolysis: a hitherto undescribed disease occurring in alcoholic and malnourished patients. AMA Arch Neurol Psychiatry. 1959;81:154-72.

2. Dagur G, Khan SA. Current concepts in pontine myelinolysis: review of literature. Transl Biomed. 2015;6:4.

3. O'Malley G, Moran C, Draman MS, King T, Smith D. Central pontine myelinolysis complicating treatment of the hyperglycaemic hyperosmolar state. Ann Clin Biochem. 2008;45:440-3.

4. Bähr M, Sommer $\mathrm{N}$, Petersen $\mathrm{D}$, Wiethölter $\mathrm{H}$, Dichgans J. Central pontine myelinolysis associated with low potassium levels in alcoholism. J Neurol. 1990;237:275-6.

5. King J, Rosner M. Osmotic demyelination syndrome. Am J Med Sci. 2010;339:561-7.
6. Turnbull J, Lumsden D, Siddiqui A, Lin J, Lim M. Osmotic demyelination syndrome associated with hypophosphataemia: 2 cases and a review of literature. Acta Paediatr. 2013;102:e164-e168168.

7. Rodríguez-Velver KV, Soto-Garcia AJ, Zapata-Rivera MA, Montes-Villarreal J, Villarreal-Pérez JZ, Rodríguez-Gutiérrez R. Osmotic demyelination syndrome as the initial manifestation of a hyperosmolar hyperglycemic state. Case Rep Neurol Med. 2014;2014:1-5.

8. Pliquett RU, Noll A, Ibe R, Katz A, Ackmann C, Schreiber A, et al. Hyperglycemia-related central pontine demyelinization after a binge-eating attack in a patient with type- 2 diabetes: a case report. BMC Endocr Disord. 2018;18:18.

9. Burns J, Kosa S, Wijdicks E. Central pontine myelinolysis in a patient with hyperosmolar hyperglycemia and consistently normal serum sodium. Neurocrit Care. 2009;11:251-4.

10. Umpierrez G, Korytkowski M. Diabetic emergencies-ketoacidosis, hyperglycaemic hyperosmolar state and hypoglycaemia. Nat Rev Endocrinol. 2016;12:222-32.

11. Chua H, Schneider A, Bellomo R. Bicarbonate in diabetic ketoacidosis-a systematic review. Ann Intensive Care. 2011;1:1-12.

12. Kitabchi A, Umpierrez G, Miles J, Fisher J. Hyperglycemic crises in adult patients with diabetes. Diabetes Care. 2009;32:1335-433.

13. Glaser N, Barnett P, McCaslin I, Nelson D, Trainor J, Louie J, et al. Risk factors for cerebral edema in children with diabetic ketoacidosis. The Pediatric Emergency Medicine Collaborative Research Committee of the American Academy of Pediatrics. N Engl J Med. 2001;344:264-9.

14. Chang KY, Lee IH, Kim GJ, Cho K, Park HS, Kim HW. Plasma exchange successfully treats central pontine myelinolysis after acute hypernatremia from intravenous sodium bicarbonate therapy. BMC Nephrol. 2014;15:56.

15. Lohr J. Osmotic demyelination syndrome following correction of hyponatremia: association with hypokalemia. Am J Med. 1994;96:408-13.

16. Koul PA, Khan UH, Jan RA, Shah S, Qadri AB, Wani $\mathrm{B}$, et al. Osmotic demyelination syndrome following slow correction of hyponatremia: possible role of hypokalemia. Indian $J$ Crit Care Med. 2013;2013(17):231-3.

17. Sugimoto T, Murata T, Omori M, Wada Y. Central pontine myelinolysis associated with hypokalaemia 
in anorexia nervosa. J Neurol Neurosurg Psychiatry. 2003;74:353-5.

18. Spasovski G, Vanholder R, Allolio B, Annane D, Ball $\mathrm{S}$, Bichet $\mathrm{D}$, et al. Clinical practice guideline on diagnosis and treatment of hyponatraemia. Eur J Endocrinol. 2014;170:G1-47.
19. Verbalis JG, Goldsmith SR, Greenberg A, Korzelius C, Schrier RW, Sterns RH, et al. Diagnosis, evaluation, and treatment of hyponatremia: expert panel recommendations. Am J Med. 2013;126:S1-42. 